\title{
Occupational Health Problems, Workplace Environment and Utilization of Personal Protective Equipment among Welders of Banepa Municipality, Nepal
}

\author{
Joshi $\mathbf{M}^{1}$, Dhakal $\mathbf{G}^{2}$, Shrestha $\mathbf{S}^{3}$
}

${ }^{1}$ BNS, Nepalese Army Institute of Health Sciences, College of Nursing, Kathmandu, Nepal, ${ }^{2}$ Associate Professor, Nepalese Army Institute of Health Sciences, College of Nursing, Kathmandu, Nepal, ${ }^{3}$ Professor, Nepalese Army Institute of Health Sciences, College of Nursing, Kathmandu, Nepal

\section{ABSTRACT}

Introduction: Welding is a hazardous occupation where welders are exposed to a variety of work-related hazards. These hazards might cause occupational health problems. Safe working environment and utilization of personal protective equipment (PPE) play a vital role in preventing problems and promoting their health, safety and wellbeing. This study aimed to identify the prevalence of occupational health problems, workplace environment and utilization of personal protective equipment among welders.

Methods: A descriptive cross- sectional study design was used for the study. Data was collected from purposively selected 130 welders of 35 metal workshops in Banepa Municipality. By using semi-structured interview schedule, face to face interview was taken with each of them from May-June, 2019. An observational checklist was used to collect information on the workplace environment of selected metal workshops. Data was analyzed by using Statistical Package for Social Sciences (SPSS) version 20 and described by using descriptive and inferential statistical methods.

Results: The study identified that 129 welders (99.2\%) experienced accidents and injuries followed by eye and ear problems (128, 98.4\%). Amongst all personal protective equipment, protective goggles was available in all 35 metal workshops and insulated gloves in 25 workshops $(71.4 \%)$. Similarly, $118(90.6 \%)$ welders always used safety goggles, $53(41 \%)$ sometimes used facemasks and $85(65.4 \%)$ never used helmets while working. Only 9 workshops (25.7\%) had first aid kits available with no expired products and $4(11.4 \%)$ had kept fire extinguishers in easily accessible locations. Among 35, 34 workshops (97.1\%) did not have safety guidelines for their workers. Conclusion: Welders who work in metal workshops experience different types of occupational health problems and do not use all types of personal protective equipment (PPE) for their protection. Hence, metal workshops should develop safety guidelines for their workers and strictly implement it to prevent occupational health problems.

Key words: metal workshop, occupational health problems, personal protective equipment, welders, welding.

DOI: https://doi.org/10.3126/ijosh.v10i2.30175

Date of submission: 29.06 .2020

Date of acceptance: 29.09 .2020

\section{Corresponding Author}

Gita Dhakal Chalise,

Associate Professor,

Nepalese Army Institute of Health Sciences, College of Nursing, Kathmandu, Nepal

Email: gita.dhakal@gmail.com,

Contact: 9841777554

Orcid ID: https://orcid.org/0000-0001-9678-8557

\section{Introduction}

t is estimated that more than one million workers are employed as welders worldwide with more than three million performing welding intermittently as part of their work duties. ${ }^{1}$ According to International Labor Organization (ILO), 0.2 to 2 percent of the total workforce is engaged in welding in typical industrialized countries. Majority of welders are employed in the transport equipment, manufacturing, building construction, mining and metallurgical industries. ${ }^{2}$

\section{cc) (7) (8)}

This journal is licensed under a Creative Commons AttributionNon Commercial 4.0 International License. 
Welding involves joining of metal pieces by means of a molten flux produced by heat or pressure or both. ${ }^{3}$ Therefore it is associated with various inherent occupational hazards that contribute to acute and chronic health effects on them. They can be fatal due to electric shock or exposure to cadmium fumes, there may also be delayed effects such as, lung changes over time. ${ }^{4,5}$ Use of PPE is a key component of workplace health and safety practices as these play a vital role in ensuring the overall health and safety of welders. Where health risks cannot be avoided or the working technique cannot be improved, the use of appropriate PPE can be an effective measure to protect the health of workers. ${ }^{6}$

Due to rapid urbanization and industrialization, welding has become an essential part of everyday life. It is a very common operation in many industries and workplaces. Welders are among the most neglected groups of workers and they suffer from various work-related problems as there are environmental hazards as well as inadequate safety in most of the welding workshops. ${ }^{7,8,9}$ Poor working environment i.e., inadequate premises, unsatisfactory welfare facilities, as well as practically non-existent occupational health services are causing large human and material losses, which burden the productivity of national economies, impair health and general well-being as well as the quality of life of informal workers like welders and their families. ${ }^{10}$ Therefore, it is the responsibility of workshop owners to create a clean, safe, and comfortable working environment for their workers.

Therefore, the objective of this study was to find out the prevalence of occupational health problems, workplace environment and utilization of personal protective equipment among welders. The finding of this study might be helpful to the authority of the metal workshop association for designing and implementing appropriate programs for occupational health and safety of the welders.

\section{Methods}

Descriptive cross- sectional study was conducted among the welders from different metal workshops of Banepa Municipality from May-June 2019. From the inventory of National Greel Industries Association, there were around 100 metal workshops with at least 3-4 welders working in each workshop in Banepa. A list of these 100 metal workshops were made, then, from the list, 35 metal workshops were selected using a simple random sampling technique.

The sample size was 130, calculated at $95 \%$ confidence interval, taking $7 \%$ allowable error which was based on $21.1 \%$ prevalence rate of occupational health problems among the welders of Dharan in 2018. ${ }^{11}$ All welders of the 35 randomly selected metal workshops who were willing to participate and available at the time of data collection were included in the study.

Ethical approval for the research study was taken from the Institutional Review Committee (IRC) of Nepalese Army Institute of Health Sciences (NAIHS). Then, written permission for data collection was taken from the president of metal workshop association i.e. National Greel Industries Association and each selected metal workshops. Informed written consent for data collection was obtained from each respondent and face to face interview was taken by using a semi-structured questionnaire in Nepali version. The questionnaire consisted of three parts. First part was about socio-demographic and work related characteristics of welders, second part was about their occupational health problems and third part was about utilization of personal protective equipment by them. Workplace environment was observed using an observational checklist by the first author after finishing interview with welders. Data analysis was done by using the SPSS version 20. Descriptive statistics i.e. frequency, percentage, mean, standard deviation and inferential statistics i.e. Chi-square test and Fisher exact test were used to analyze the data. The findings are presented in tables.

\section{Results}

In this study, 19 respondents (14.6\%) were aged less than 16 years and the mean age was 24.46 years (SD \pm 8.047$)$. All $130(100 \%)$ respondents were male, $43(33.0 \%)$ had completed secondary level education and 72 (55.4\%) were married. Similarly 51 respondents $(39.3 \%)$ had work experience of less than five years (mean 5.75, SD \pm 5.912 ) and 77 respondents $(59.2 \%)$ used to work for 5-10 hours per day with mean working hour of 10.20 (SD \pm 1.727$)$. In this study, 119 respondents $(91.5 \%)$ didn't have any formal education or training related to welding (Table 1).

Table 2 shows that all 130 respondents had experienced occupational health problems. In this study, 129 respondents reported occupational health problems such as accidents and injuries (99\%) 
followed by eye and ear problems (128, 98.4\%), skin problems $(112,86 \%)$, metallic fume fever $(107,82.3 \%)$, musculoskeletal problems $(91,70 \%)$ and respiratory problems (49, 37.69\%).

In this study, no significant association of respondents' age, educational level, work experience and working hours per day with occupational health problems were found ( $p$ value is $>0.05$ ).

In this study, 118 respondents $(90.6 \%)$ had always used safety goggles while at work. Similarly 53 respondents $(40.7 \%)$ had sometimes used facemask and equal percentage of respondents sometimes used insulated gloves also. But 124 respondents (95.3\%) had never used ear safety devices and 120 (92.3\%) never used heat resistant apron during their work (Table 3).

This study identified that protective goggles were available in all 35 workshops (100\%) and insulated gloves in 25 workshops (71.4\%). Similarly hand shield was not available in 34 workshops (97.1\%), heat resistant apron in $33(94.3 \%)$ and ear safety devices in 32 workshops (91.4\%) (Table 4).

While observing the workplace environment of 35 metal workshops, 31 (88.6\%) had provision of adequate lighting and cross ventilation. Only $4(11.4 \%)$ had fire extinguishers readiness in easily accessible location and $9(25.7 \%)$ had first aid kit available with no expired products. Almost all i.e. 34 workshops (97.1\%) did not have safety guidelines for their workers (Table 5).

Table 1: Respondent's Socio-demographic and Work Related Variables

\begin{tabular}{|c|c|c|}
\hline Variables & Frequency & Percent \\
\hline \multicolumn{3}{|c|}{ Completed age (in years) * } \\
\hline$<16$ & 19 & 14.6 \\
\hline $16-20$ & 13 & 10.0 \\
\hline $21-25$ & 13 & 10.0 \\
\hline $26-30$ & 8 & 6.2 \\
\hline $31-35$ & 15 & 11.5 \\
\hline $36-40$ & 15 & 11.5 \\
\hline $41-45$ & 12 & 9.2 \\
\hline $46-50$ & 10 & 7.7 \\
\hline $51-55$ & 14 & 10.8 \\
\hline $55-60$ & 11 & 8.5 \\
\hline \multicolumn{3}{|l|}{ Education level } \\
\hline Informal education & 22 & 16.9 \\
\hline Primary education & 34 & 26.2 \\
\hline Lower secondary & 28 & 21.5 \\
\hline Secondary level & 43 & 33.0 \\
\hline Bachelor and above & 3 & 2.3 \\
\hline \multicolumn{3}{|l|}{ Marital status } \\
\hline Single & 58 & 44.6 \\
\hline Married & 72 & 55.4 \\
\hline \multicolumn{3}{|c|}{ Work experience (in years)† } \\
\hline$\leq 5$ & 51 & 39.3 \\
\hline $6-10$ & 38 & 29.2 \\
\hline$>10$ & 41 & 31.5 \\
\hline \multicolumn{3}{|c|}{ Working hours (per day) \# } \\
\hline $5-10$ & 77 & 59.2 \\
\hline$>10$ & 53 & 40.8 \\
\hline \multicolumn{3}{|c|}{ Training/education received } \\
\hline Yes & 11 & 8.5 \\
\hline No & 119 & 91.5 \\
\hline
\end{tabular}

${ }^{*}$ Mean age $=24.46(\mathrm{SD} \pm 8.047)$

†Mean work experience $=5.75(\mathrm{SD} \pm 5.912)$

\#Mean working hours per day $=10.20(\mathrm{SD} \pm 1.727)$ 
Occupational Health Problems, Workplace Environment and Utilization of Personal Protective Equipment among ...

Table 2: Type of Occupational Health Problems experienced by Respondents within Previous Six Months Period

\begin{tabular}{|c|c|c|}
\hline Type of health problems* & Frequency & Percent \\
\hline \multicolumn{3}{|c|}{ Accidents and injuries $(n=129)$} \\
\hline Burn & 108 & 83.7 \\
\hline Electric shock & 104 & 80.6 \\
\hline Cut injury & 101 & 78.2 \\
\hline Poisoning & 8 & 6.2 \\
\hline \multicolumn{3}{|c|}{ Ear and eye problems $(n=128)$} \\
\hline Red eye & 119 & 92.9 \\
\hline Intense tear & 96 & 75.0 \\
\hline Eye pain & 82 & 64.0 \\
\hline Tinnitus & 31 & 24.2 \\
\hline Hearing loss & 29 & 22.6 \\
\hline \multicolumn{3}{|l|}{ Skin problems (n=112) } \\
\hline Ulcer & 97 & 86.6 \\
\hline Itching & 51 & 45.5 \\
\hline Redness of skin & 41 & 36.6 \\
\hline \multicolumn{3}{|l|}{ Metallic fumes fever $(n=107)$} \\
\hline General body weakness & 79 & 73.8 \\
\hline Flu like symptoms & 71 & 66.3 \\
\hline Sweet metallic taste & 31 & 28.7 \\
\hline \multicolumn{3}{|c|}{ Musculoskeletal problems $(n=91)$} \\
\hline Back pain & 83 & 91.2 \\
\hline Muscle sprain & 17 & 18.6 \\
\hline \multicolumn{3}{|l|}{ Respiratory problems $(n=49)$} \\
\hline Chronic cough & 36 & 73.4 \\
\hline Shortness of breath & 27 & 55.1 \\
\hline
\end{tabular}

*Multiple responses

Table 3: Type of Personal Protective Equipment used by Respondents

\begin{tabular}{|c|c|c|c|c|}
\hline Equipment & $\begin{array}{c}\text { Always } \\
\text { f (\%) }\end{array}$ & $\begin{array}{c}\text { Sometimes } \\
f(\%)\end{array}$ & $\begin{array}{c}\text { Never } \\
\text { f (\%) }\end{array}$ & Total \\
\hline Safety goggles & $118(90.6)$ & $12(9.2)$ & - & $130(100)$ \\
\hline Insulated gloves & $11(8.5)$ & $54(41.5)$ & $65(50.0)$ & $130(100)$ \\
\hline Ear safety devices & $2(1.5)$ & $4(3.1)$ & $124(95.4)$ & $130(100)$ \\
\hline Helmet & $10(7.7)$ & $35(26.9)$ & $85(65.4)$ & $130(100)$ \\
\hline Safety shoes & $4(3.0)$ & $21(16.2)$ & $105(80.8)$ & $130(100)$ \\
\hline Face masks & $15(11.5)$ & $53(40.8)$ & $62(47.7)$ & $130(100)$ \\
\hline Heat resistant apron & $4(3.1)$ & $6(4.6)$ & $120(92.3)$ & $130(100)$ \\
\hline
\end{tabular}

Table 4: Availability of Personal Protective Equipment in Metal Workshops $n=35$

\begin{tabular}{lcc}
\hline Variables & $\begin{array}{c}\text { Yes } \\
\mathbf{f}(\%)\end{array}$ & $\begin{array}{c}\text { No } \\
\mathbf{f}(\%)\end{array}$ \\
\hline Protective goggles & $35(100)$ & - \\
Insulated gloves & $25(71.4)$ & $32(91.4)$ \\
Ear safety devices & $3(8.6)$ & $17(48.6)$ \\
Helmet & $18(51.4)$ & $30(85.7)$ \\
Safety shoes & $5(14.3)$ & $20(57.1)$ \\
Mask & $15(42.9)$ & $33(94.3)$ \\
Heat resistant apron & $2(5.7)$ & $34(97.1)$ \\
\hline Hand-shield & $1(2.9)$ & \\
\hline
\end{tabular}


Table 5: Workplace Environment of Metal Workshops n=35

\begin{tabular}{lcc}
\hline Variables & $\begin{array}{c}\text { Yes } \\
\mathbf{f}(\%)\end{array}$ & $\begin{array}{c}\text { No } \\
\mathbf{f}(\%)\end{array}$ \\
\hline Adequate lighting and cross ventilation are present in workshop & $31(88.6)$ & $4(11.4)$ \\
Work spaces is clean and free from obstruction & $17(48.6)$ & $18(51.4)$ \\
\hline First aid kit is available with no expired products inside & $9(25.7)$ & $26(74.3)$ \\
Fire extinguishers readiness is in easily accessible locations & $4(11.4)$ & $31(88.6)$ \\
Gas cylinders are stored away from all heat sources & $4(11.4)$ & $31(88.6)$ \\
Gas cylinders are kept in a well-ventilated, dry location & $4(11.4)$ & $31(88.6)$ \\
away from any combustible items & $1(2.9)$ & $34(97.1)$ \\
\hline There is availability of safety guidelines &
\end{tabular}

\section{Discussion}

In the present study, more than one-third (39.3\%) of welders had work experience of less than five years (mean 5.75, SD \pm 5.912). The finding of this study is consistent with the study conducted among 300 welders from Eastern Nepal where their mean work experience was 6.94 years. ${ }^{12}$ Regarding working hours, $59.2 \%$ of respondents used to work for $5-10$ hours and $41 \%$ used to work for more than 10 hours per day (mean working hour $10.20, S D \pm 1.727$ ). This finding is consistent with the study conducted in Uganda among 218 welders, where the mean working hours of welders was 11.6 hours. ${ }^{13}$ According to Nepal Labor Act 2074, the maximum permissible working hours for labor is 48 hours a week but this study found that the mean working hours per day for welders was more than recommended hours. ${ }^{14}$ This might be due to extra wages received from the overtime work, welding work at different working site and no policy and guidelines regarding working hours in metal workshops.

In this study, $91.5 \%$ didn't have any formal education and training related to welding. This study finding is consistent with the study conducted in Pakistan among 70 welders where $91.4 \%$ didn't have any training and education regarding welding work. ${ }^{15}$ Similarly, in the study conducted in South India among 209 respondents, $80 \%$ of welders didn't have any education and training regarding welding work. ${ }^{16}$ From all these studies, it was found that most of the welders of Southern Asia like Nepal, India and Pakistan have started their welding occupation with no formal education and training. Most of them have learned through observation and experience. Limited education and training regarding welding work might be associated with the rise of occupational health problems among welders.
In this study, all respondents have experienced different types of occupational health problems. Among them, $99 \%$ of respondents experienced work-related accidents and injuries. This finding is consistent with the study findings from Eastern Nepal and Uganda. 11, 13 Other most common problem experienced by respondents in this study was eye and ear problems (98.5\%). In Canada, 53.3\% welders had at least one ocular symptom. ${ }^{17}$ Another study from Nigeria among industrial welders identified that the prevalence of work-related ocular injury by history only was $52.2 \%$. Similarly, $60.2 \%$ had either a history or physical evidence of ocular injury. The commonest ocular injuries included corneal opacity $(62 \%)$, corneal foreign body $(22 \%)$ and traumatic iritis $(7 \%) .{ }^{18}$ Welders are continuously exposed to welding fumes and gases, electric current, flying sparks, sharp edges of metals, fire and heat while at work. They also worked for excess working hours and go to different sites like building construction, industrial sites, vehicle repair site, road and bridge construction and hydropower construction site. ${ }^{2,3}$ All these hazards and risk factors might be associated with these problems among them.

Welding in a static awkward or horizontal posture may result in musculoskeletal problems, such as back pain, strains and sprains and fume and gases emitted during welding might cause various respiratory problems. In the present study, musculoskeletal problems (70\%) and respiratory problems (37.69\%) were also prevalent among welders. Similar findings were identified in a study conducted among Pakistani gas and arc welders also. ${ }^{19}$ Another study conducted among two groups (welders Vs control groups) in Sri Lanka identified that chronic bronchitis (27\% in welders, $7 \%$ in controls) was the common respiratory problem. Here, respiratory problems were found significantly higher among 
welders than control group. ${ }^{20}$ Similar study conducted among welders from two cities in Quebec, Canada identified that the co-occurrence of possible metallic fume fever together with welding related respiratory symptoms suggestive of occupational asthma was $5.8 \% .{ }^{21}$ There are various other studies which supports all these findings. ${ }^{22-27}$ The study shows no significant association of socio-demographic and work related factors with occupational health problems. But the study conducted in Eastern Nepal among 300 welders identified significant association of age of respondents, duration of employment and working hours with different occupational health problems. ${ }^{12}$

Welders work in outdoor or indoor workplaces and in open or confined spaces. In some conditions, welding processes are carried out in confined spaces where the welding work area is surrounded on most sides by walls and there is no sufficient space for the installation of a conventional exhaust hood. ${ }^{28}$ In welding environments, employers are responsible to ensure the safety and health of welders and take proper measures for their protection. In the present study, it was found that all 35 metal workshops didn't have all types of personal protective equipment to prevent occupational health problems for their workers but they have few i.e. protective goggles $(100 \%)$, insulated gloves $(71.4 \%)$, helmet $(51.4 \%)$, masks $(42.9 \%)$, safety shoes (14.3\%), ear safety devices (8.6\%) and heat resistant apron $(5.7 \%)$. During observation of the workplace environment, $88.6 \%$ had provision of adequate lighting and cross ventilation, $11.4 \%$ had fire extinguishers readiness in easily accessible location, $25.6 \%$ had first aid kit available with no expired products and $11.4 \%$ had stored gas cylinders away from heat sources. Almost all $(97.1 \%)$ workshops did not have safety guidelines for their workers. These findings are supported by a study conducted in Jos metropolis where all the workshops were well ventilated and $98.0 \%$ were well-lit. None of the workshops had fire extinguishers, first aid boxes nor did they label hazardous substances. Only $82.0 \%$ workshops provided goggles for the workers while no helmet, apron nor hearing protection was provided by any of the workshops assessed. ${ }^{6}$

Fume and gases emitted during welding pose a threat to human health while welding. ${ }^{28}$ Therefore it is essential that welders should wear personnel protective equipment to prevent different adverse effects. In this study, personal protective equipment utilized by respondents were safety goggles (100\%), face masks (52.3\%) heat resistant apron (7.6\%) and ear safety devices $(4.6 \%)$. Similar study conducted among 150 welders in unorganized welding units in Vellore, India identified that $84 \%$ welders used crude hand shields, $61.3 \%$ used safety glasses but of the non-auto darkening type, and only $0.7 \%$ reported wearing a fireproof apron. None of the welders used recommended hand shields, safety helmets, autodarkening glasses, fire resistant caps, fire proof clothing, or ear plugs. ${ }^{29}$ The study conducted among 102 workers from 28 small-scale industries (i.e., vehicle repair, welding, and paint) in Jeddah identified that workers used knee joint mats (50\%), welding shields $(50 \%)$, safety glasses $(33.3 \%)$, gloves $(27.5 \%)$, face masks $(26.5 \%)$, safety shoes $(10.8 \%)$ and ear plugs/ muffs $(8.8 \%) \cdot{ }^{9}$ As per code of practice issued by ILO on safety and health in the iron and steel industry, workers should be provided with suitable and sufficient PPE (i.e. helmet, face shield or eye protectors, protective gloves, respirators, hearing protectors, protective clothing) for controlling the risk at source or minimizing the risk. These should be provided and maintained by the employer, without cost to the workers. Employers should ensure that the workers who are required to wear PPE are fully informed and are given adequate training in the selection, wearing, maintenance and storage of this equipment. ${ }^{2}$

\section{Limitations}

Prevalence of occupational health problems were based on self-reported data of respondents. No any objective instruments were used to measure the welding related health problems.

\section{Conclusion}

Welders work without any formal training therefore they might be unaware of safe working practices to protect their health. They experience different types of occupational health problems i.e. accidents and injuries, eye and ear problems, skin problems, metallic fumes fever, musculoskeletal problems and respiratory problems. At work, they use few personnel protective equipment (PPE) only and most welding workshops do not have availability of all types of PPE for their workers. Workshops do not have safety guidelines for their workers therefore compliance on using all types of PPE is low. The employers as well as welders need short-term training to make them aware about the use of PPE for prevention of welding related occupational health problems. 


\section{References}

1. Isah EC, Okojie OH. Occupational health problems of welders in Benin City, Nigeria. Journal of Medicine and Biomedical Research. 2006 Jun;5(1):64-9. ISSN: 1596-6941. Available from: http://www.bioline. org.br/pdf?jm06011

2. International Labour Organisation. Sectoral Activities Programme. Code of practice on safety and health in the iron and steel industry: meeting of experts to develop a revised code of practice on safety and health in the iron and steel industry. Geneva: International Labour Office; 2005:106. Report No MEISI/2005/8; 2005.

3. Lyndon GS. Welding and thermal cutting. Encyclopedia of occupational health and safety. $3^{\text {rd }}$ ed. Geneva: International Labour Organization.1983: 2290-5.

4. Joseph N, Venkatesh V, Akash SK, Hegde S, Moras E, Shenoy NP. Occupation hazards - pattern, awareness and preventive measures among welders from an unorganized sector in India. Journal of Clinical and Diagnostic Research. 2017 May;11(5): LC23-LC28. doi: 10.7860/JCDR/2017/24977.9879

5. MacLeod JS, Harris MA, Tjepkema M, Peters PA, Demers PA. Cancer risks among welders and occasional welders in a national populationbased cohort study: Canadian census health and environmental cohort. Safety and Health at Work. 2017 Sep 1;8(3):258-66. doi: 10.1016/j. shaw.2016.12.001

6. Balkhyour MA, Ahmad I, Rehan M. Assessment of personal protective equipment use and occupational exposures in small industries in Jeddah: health implications for workers. Saudi Journal of Biological Sciences. 2019 May 1;26(4):653-9. doi:10.1016/j. sjbs.2018.06.011

7. Tagurum YO, Gwomson MD, Yakubu PM, Igbita JA, Chingle MP, Chirdan OO. Awareness of occupational hazards and utilization of PPE amongst welders in Jos metropolis, Nigeria. International Journal of Research in Medical Sciences. 2018 Jul;6(7):222733. doi: http://dx.doi.org/10.18203/2320-6012. ijrms20182808

8. Antonini JM. Health effects of welding. Critical Reviews in Toxicology. 2003 Jan 1;33(1):61-103. doi: https://doi.org/10.1080/713611032

9. Beyene Gebrezgiabher B, Tetemke D, Yetum T. Awareness of occupational hazards and utilization of safety measures among welders in Aksum and Adwa towns, Tigray region, Ethiopia, 2013. Journal of Environmental and Public Health. 2019 Jan 21;2019. doi: https://doi.org/10.1155/2019/4174085
10. Forastieri V. Improvement of working conditions and environment in the informal sector through safety and health measures. Geneva: International Labour Office. 1999 Jul:1-17.

11. Ghimire A, Budhathoki SS, Niraula SR, Shrestha A, Pokharel PK. Work-related injury among welders working in metal workshops of Dharan municipality, Nepal. Journal of Nepal Health Research Council. 2018 Jul 5;16(2):156-9. doi: http://dx.doi.org/10.3126/ jnhrc.v16i2.20302

12. Budhathoki SS, Singh SB, Sagtani RA, Niraula SR, Pokharel PK. Awareness of occupational hazards and use of safety measures among welders: a crosssectional study from eastern Nepal. BMJ open. 2014 May 1;4(6):e004646. doi:10.1136/bmjopen-2013004646

13. Okuga M, Mayega R, Bazeyo W. Small-scale industrial welders in Jinja Municipality, Ugandaawareness of occupational hazards and use of safety measures. African Newsletter on Occupational Health and Safety. 2012 Sep;22(2):35-6. Available from: http://www.riskreductionafrica.org/wpcontent/ uploads/2015/01/AfricanNewsletter2_2012.pdf

14. Nepal Labor Act 2074. p 8. Available from: http:// dol.gov.np/ckeditor/kcfinder/upload/files/श्रम ऐन २०७४.pdf

15. Hassan SM, Nasir U, Anwar K, Talib U. An assessment of the level of awareness and reported complaints regarding occupational health hazards and the utilization of personal protective equipment among the welders of Lahore, Pakistan. International Journal of Occupational and Environmental Health. 2017 Apr 3;23(2):98-109. doi:10.1080/10773525.201 8.1426259

16. Kumar SG, Dharanipriya A, Kar SS. Awareness of occupational injuries and utilization of safety measures among welders in coastal South India. The International Journal of Occupational and Environmental Medicine. 2013 Oct 15;4:172-7. Available from: https://www.theijoem.com/ijoem/ index.php/ijoem/article/view/252/403

17. El-Zein M, Malo JL, Infante-Rivard C, Gautrin D. Prevalence and association of welding related systemic and respiratory symptoms in welders. Occupational and Environmental Medicine. 2003 Sep 1;60(9):655-61. Available from: https://oem.bmj.com/ content/oemed/60/9/655.full.pdf

18. Fiebai B, Awoyesuku EA. Ocular injuries among industrial welders in Port Harcourt, Nigeria. Clinical Ophthalmology. 2 September 2011;5:1261-3. doi: $10.2147 / O P T H . S 20297$

19. Hossein E, Reza K, Abolfazl M. Comparative survey of work related musculoskeletal disorders 
(WRMDs) prevalence and related factors in Iranian welders. Pakistan Journal of Medical Sciences. 2011 Apr 1;27:282-5. Available from: https://www. researchgate.net/profile/Abolfazl_Mohammadbeigi/ publication/228509946_Comparative_survey_ of_work_related_musculoskeletal_disorders_ WRMDs_prevalence_and_related_factors_in_ Iranian_welders/links/0fcfd50ed83c34ccfa000000/ Comparative - surve y - of - work-relatedmusculoskeletal-disorders-WRMDs-prevalence-andrelated-factors-in-Iranian-welders.pdf

20. Jayawardana P, Abeysena C. Respiratory health of welders in a container yard, Sri Lanka. Occupational Medicine. 2009 Jun 1;59(4):226-9. doi: https://doi. org/10.1093/occmed/kqn166

21. El-Zein M, Infante-Rivard C, Malo JL, Gautrin D. Is metal fume fever a determinant of welding related respiratory symptoms and/or increased bronchial responsiveness? A longitudinal study. Occupational and Environmental Medicine. 2005 Oct 1;62(10):68894. doi: 10.1136/oem.2004.018796

22. Hariri A, Paiman NA, Leman AM, Md Yusof MZ. Pulmonary adverse effects of weld bonding process by Malaysia's automobile assembly welders. Procedia Engineering. 2014 Apr 12;68(2013):299304. doi: 10.1016/j.proeng.2013.12.183

23. Dierschke $\mathrm{K}$, Isaxon $\mathrm{C}$, Andersson UB, Assarsson E, Axmon $A$, Stockfelt $L$ et.al. Acute respiratory effects and biomarkers of inflammation due to weldingderived nanoparticle aggregates. International Archives of Occupational and Environmental Health. 2017 Jul 1;90(5):451-63. doi: https://doi.org/10.1007/ s00420-017-1209-z
24. Jonsson LS, Tinnerberg $H$, Jacobsson $H$, Andersson $\mathrm{U}$, Axmon A, Nielsen J. The ordinary work environment increases symptoms from eyes and airways in mild steel welders. International Archives of Occupational and Environmental Health. 2015 Nov 1;88(8):113140. doi: https://doi.org/10.1007/s00420-015-1041-2

25. Koh DH, Kim JI, Kim KH, Yoo SW. Welding fume exposure and chronic obstructive pulmonary disease in welders. Occupational Medicine. 2015 Jan 1;65(1):72-7. doi: https://doi.org/10.1093/occmed/ kqu136

26. Hedmer M, Karlsson JE, Andersson U, Jacobsson $\mathrm{H}$, Nielsen J, Tinnerberg $\mathrm{H}$. Exposure to respirable dust and manganese and prevalence of airways symptoms, among Swedish mild steel welders in the manufacturing industry. International Archives of Occupational and Environmental Health. 2014 Aug 1;87(6):623-34. doi: https://doi.org/10.1007/s00420013-0896-3

27. Chauhan A, Anand T, Kishore J, Danielsen TE, Ingle GK. Occupational hazard exposure and general health profile of welders in rural Delhi. Indian Journal of Occupational and Environmental Medicine. 2014 Jan;18(1):21-6. doi: 10.4103/0019-5278.134953

28. Golbabaei F, Khadem M. Air pollution in welding processes-assessment and control methods. Current Air Quality Issues. 2015 Oct 21:33-63. doi: $10.5772 / 59793$

29. Alexander V, Sindhu KN, Zechariah P, Resu AV, Nair $S R$, Kattula $D$ et.al. Occupational safety measures and morbidity among welders in Vellore, Southern India. International Journal of Occupational and Environmental Health. 2016 Oct 1;22(4):300-6. doi: $10.1080 / 10773525.2016 .1228287$ 